\title{
Effect of Methyl- $\beta$-Cyclodextrin and Fertilization Promoting Peptide on Capacitation of Boar Spermatozoa in a Protein-Free Medium
}

\author{
Hiroaki FUNAHASHI ${ }^{1)}$ \\ 1) Department of Animal Science, Okayama University, 1-1-1 Tsushima-naka, Okayama 700- \\ 8530, Japan
}

\begin{abstract}
The present study was undertaken to examine the effect of methyl- $\beta$-cyclodextrin (MBCD) and fertilization promoting peptide (FPP; pGlu-Glu-ProNH $\mathrm{H}_{2}$ ) on the capacitation and acrosome reaction of boar spermatozoa in a protein-free medium. After washing with a protein-free medium, ejaculated spermatozoa (resuspended at $1 \times 10^{6} \mathrm{cells} / \mathrm{ml}$ ) were cultured in $2 \mathrm{ml}$ of modified Medium199 containing polyvinylalcohol (mM199-PVA) supplemented or not supplemented with MBCD and/ or FPP for $2 \mathrm{~h}$ in an atmosphere of $5 \% \mathrm{CO}_{2}$ in air at $39 \mathrm{C}$. Effects of MBCD and FPP on boar spermatozoa were determined by chlortetracycline fluorescence assessment. When spermatozoa were cultured in various MBCD concentrations, capacitation was induced in a concentrationdependent manner, but spontaneous acrosome reaction was not affected. When the effect of FPP in mM199-PVA was determined, sperm capacitation was induced and spontaneous acrosome reaction was inhibited in $100 \mathrm{nM}$ FPP, regardless of the absence or presence of BSA. In the last experiment, spermatozoa were cultured in mM199-PVA supplemented with various concentrations of MBCD and/or FPP. An accelerative effect of MBCD on sperm capacitation was observed in a concentrationdependent manner even in the presence of FPP, whereas 1-2 mM of MBCD neutralized the stimulatory effect of FPP on capacitation. Furthermore, FPP inhibited spontaneous acrosome reaction even in the presence of MBCD. These results demonstrate that MBCD and PFF can induce capacitation of boar spermatozoa in a protein-free medium and that FPP alone also inhibits spontaneous acrosome reaction.
\end{abstract}

Key words: Pig, Spermatozoa, Capacitation, Cholesterol efflux

(J. Reprod. Dev. 48: 57-63, 2002)

$\mathbf{E}$ fflux of cholesterol from sperm membrane is contained in the early step of capacitation in mammalian spermatozoa [1-3]. In vivo, albumin [4, 5] and high-density lipoprotein (HDL) [6-8] in oviductal fluid and follicular fluid appear to serve as an acceptor for sperm cholesterol. The albumin fraction accounts for $90 \%$ of total protein in bovine oviductal fluid [9]. Oviductal HDL, which is the only lipoprotein detected in bovine oviductal fluid, is increased during the period corresponding to

Accepted for publication: October 10, 2001

Correspondence: H. Funahashi estrus [6]. In in-vitro fertilization (IVF) systems, BSA in preincubation and/or fertilization media is believed to act as a cholesterol acceptor [5, 10-12]. Recently, methyl- $\beta$-cyclodextrin (MBCD), which is a strong cholesterol acceptor, is known to stimulate the efflux of cholesterol from sperm membrane and consequently to induce capacitation of spermatozoa in a protein-free medium in mice [13, $14]$, cattle [14] and man [15, 16]. This evidence emphasizes the importance of cholesterol efflux from sperm membrane at capacitation and the role of BSA as a cholesterol acceptor in IVF systems. 
But, it is not known yet if boar spermatozoa respond to $M B C D$, as observed in mice, cattle and man. Furthermore, it is not clear how spontaneous capacitation is induced after efflux of sperm cholesterol.

Recently we showed that both fertilization promoting peptide (FPP; pGlu-Glu-ProNH $\mathrm{N}_{2}$ ) and adenosine induced capacitation and inhibited spontaneous acrosome reaction of boar spermatozoa via a similar signal pathway $[17,18]$. Since this phenomenon was observed in the presence of BSA, it is not clear if efflux of cholesterol from sperm membrane is required for expression of the FPP effect. Furthermore, although the response of mouse spermatozoa to FPP involves protein tyrosine phosphorylation [19], treatment with MBCD also induces the phosphorylation in mouse and bull spermatozoa [14]. The effect of FPP in the presence of MBCD is not clear.

The present study was undertaken to examine the effect of MBCD and FPP on the capacitation and acrosome reaction of boar spermatozoa in a protein-free medium. Furthermore, the effect of FPP in the presence of various concentrations of MBCD on sperm response was also determined.

\section{Materials and Methods}

\section{Culture media}

The basic medium for the incubation of spermatozoa was a modified Medium 199 (mM199) with Earle's salts (Invitrogen Corp., Carsbad, CA USA) supplemented with $12 \mathrm{mM}$ sorbitol, $3.05 \mathrm{mM}$ D-glucose, $2.92 \mathrm{mM}$ hemi-calcium lactate and 0.91 $\mathrm{mM}$ sodium pyruvate. Before use, this medium was supplemented with $0.1 \%$ polyvinylalcohol (mM199-PVA) or $0.4 \%$ BSA (mM199-BSA). Culture media were equilibrated in an atmosphere of $5 \% \mathrm{CO}_{2}$ in air at $39 \mathrm{C}$ for a minimum of $3 \mathrm{~h}$ before the start of incubation. The medium used for washing spermatozoa was modified Tyrode lactate-Hepes-polyvinylalcohol (TL-HEPES-PVA) medium [20].

FPP was prepared as described previously [17]. FPP stocks (10 $\mu \mathrm{M}$ solution in protein-free mM199) were divided into aliquots, frozen at $-30 \mathrm{C}$ and kept for up to 4 weeks. For use, stocks were thawed and diluted with medium as required. MBCD was prepared as stocks of $0.1 \mathrm{M}$ solution and stored at
-30 C. For use, stocks were thawed and diluted with medium as required.

\section{Preparation of boar spermatozoa}

Sperm-rich fractions $(30-45 \mathrm{ml})$ were collected from four Berkshire boars by the gloved hand method at a local livestock center and transported to the laboratory at 33-39 C within $2 \mathrm{~h}$ of collection. The semen samples were used immediately. For use, $5 \mathrm{ml}$ of semen was mixed with the same volume of TL-HEPES-PVA to remove seminal plasma, and then the cells were washed three times with TL-HEPES-PVA by centrifugation at $1200 \mathrm{~g}$ for $3 \mathrm{~min}$ and resuspended in TL-HEPES-PVA. After washing, the pellets containing spermatozoa were resuspended at a final concentration of $1 \times 10^{6}$ cells/ $\mathrm{ml}$ in mM199-PVA or mM199-BSA containing or not containing FPP and/or MBCD.

\section{Experiment design}

Primarily, to determine the effect of MBCD, washed spermatozoa were resuspended in $2 \mathrm{ml}$ of mM199-PVA containing various concentrations $(0$, $0.125,0.25,0.50,1.00$ and $2.00 \mathrm{mM}$ ) of MBCD and were cultured for $2 \mathrm{~h}$ in an atmosphere of $5 \% \mathrm{CO}_{2}$ in air at 39 C. In another experiment, the culture duration for spermatozoa was prolonged until $5 \mathrm{~h}$ in the absence or presence of $1 \mathrm{mM} \mathrm{MBCD}$. In all experiments as described below, the effects of MBCD on boar spermatozoa were determined by chlortetracycline (CTC) fluorescence assay after culture.

Next, to examine the effect of FPP in the absence of BSA, washed spermatozoa were resuspended to $2 \mathrm{ml}$ of mM199-BSA or mM199-PVA supplemented or not supplemented with $100 \mathrm{nM}$ FPP and were cultured for $2 \mathrm{~h}$ in an atmosphere of $5 \% \mathrm{CO}_{2}$ in air at $39 \mathrm{C}$.

Finally, to assess the effect of FPP in the presence of MBCD, washed spermatozoa were resuspended in $2 \mathrm{ml}$ of $\mathrm{mM} 199-\mathrm{PVA}$ containing various concentrations of $\operatorname{MBCD}(0,0.50,1.00$ and $2.00 \mathrm{mM})$ and FPP ( 0 and $100 \mathrm{nM})$ and were cultured for $2 \mathrm{~h}$ in an atmosphere of $5 \% \mathrm{CO}_{2}$ in air at $39 \mathrm{C}$.

\section{CTC fluorescence assessment of spermatozoa}

The methods used for CTC analysis were essentially those described by Wang et al. [21] for boar spermatozoa, with a few minor modifications. Briefly, $20 \mu \mathrm{l}$ of $100 \mu \mathrm{g} / \mathrm{ml}$ Hoechst bis-benzimide 33258 (Sigma, St. Luis, MO USA) in mM199 was 
added to $2 \mathrm{ml}$ sperm suspension. After gentle mixing, each suspension was incubated for $3 \mathrm{~min}$ at room temperature in the dark, then layered onto 3 $\mathrm{ml}$ of $3 \%(\mathrm{w} / \mathrm{v})$ polyvinylpyrolidone (PVP-40; Sigma) in TL-HEPES-PVA and centrifuged at 1400 $g$ for $5 \mathrm{~min}$. The pelleted spermatozoa were resuspended in $45 \mu \mathrm{l}$ of TL-HEPES-PVA and $45 \mu \mathrm{l}$ of this suspension was added to $45 \mu \mathrm{l}$ of CTC solution, containing $750 \mu \mathrm{M}$ CTC (Sigma), $5 \mathrm{mM}$ cysteine, $130 \mathrm{mM} \mathrm{NaCl}$ and $20 \mathrm{mM}$ Tris (pH 7.8). Sperm cells were fixed by adding $8 \mu \mathrm{l}$ of $12.5 \%$ (w/ v) paraformaldehyde in $0.5 \mathrm{M}$ Tris- $\mathrm{HCl}(\mathrm{pH} 7.4)$. The CTC solution was prepared daily. Each slide was prepared by placing $10 \mu \mathrm{l}$ of the fixed sperm suspension on a slide and one drop of $0.22 \mathrm{M} 1,4-$ diazabicyclo[2.2.2] octane (Sigma) dissolved in glycerol:TL-HEPES-PVA (9:1) which was then carefully mixed in order to retard the fading of fluorescence. A coverslip was added and sealed with colorless nail varnish.

Spermatozoa were assessed under a phasecontrast microscope, equipped with epifluorescent optics, on the same day. Each cell was first observed under ultraviolet (UV) illumination (excitation at 330-380 nm, emission at $420 \mathrm{~nm}$ ) to determine the live/dead status; the sperm cells showing bright blue staining of the nucleus were considered as dead and not counted. One hundred live sperm were then examined under blue-violet illumination (excitation at $400-440 \mathrm{~nm}$, emission at $470 \mathrm{~nm}$ ) and classified according to CTC staining patterns. The three fluorescent staining patterns identified were: $\mathrm{F}$, with uniform fluorescence over the whole sperm head; $B$, with a fluorescence-free band in the post-acrosome region; AR, with almost no fluorescence over the sperm head except for a thin band of fluorescence in the equatorial segment [21].

\section{Statistical analysis}

Statistical analyses of CTC results from 3 to 5 replicate experiments for treatment comparisons were carried out by one-way or two-way analysis of variance (ANOVA) with the STATVIEW (Abacus Concepts, Inc., Berkeley, CA, USA) program. If a $P$ value was less than 0.05 in one-way ANOVA, Fisher's protected least significant difference test was then used with the STATVIEW (Abacus Concepts, Inc.) program. All percentage data were subjected to arc sine transformation before statistical analysis. Data are expressed as the mean \pm SEM and $\mathrm{P}<0.05$ was considered to be statistically significant.

\section{Results}

As shown in Fig. 1, the incidence of intact (F pattern) and capacitated spermatozoa (B pattern) decreased and increased, respectively, in a concentration-dependent manner in the presence of MBCD. Therefore, capacitation was induced in the presence of MBCD in protein-free mM199, but there was no difference in the incidence of acrosome-reacted cells (AR pattern) among treatment groups. Furthermore, the incidence of acrosome-reacted spermatozoa (AR pattern) progressively increased when the culture duration was prolonged until $5 \mathrm{~h}$ regardless of the absence or presence of MBCD (Fig. 2). Therefore, exposure of spermatozoa to MBCD did not effect a spontaneous acrosome reaction in protein-free mM199.

The result of CTC fluorescence assessment after culture of spermatozoa in the absence or presence of $100 \mathrm{nM}$ FPP in mM199-BSA or mM199-PVA is shown in Fig. 3. The percentages of capacitated cells (B pattern) and acrosome-reacted ones (AR pattern) were higher and lower, respectively, in the

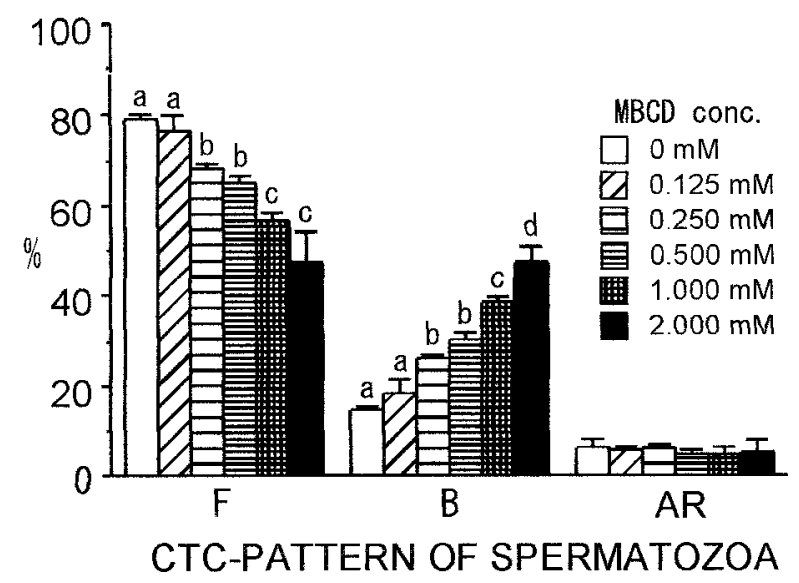

Fig. 1. Effect of $M B C D$ on sperm response in protein-free mM199 as determined by analysis of CTC fluorescence patterns in fresh boar spermatozoa. Suspensions were cultured in various concentrations of MBCD in mM199-PVA for $2 \mathrm{~h}$ in an atmosphere of $5 \% \mathrm{CO}_{2}$ in air at $39 \mathrm{C}$. Data are presented as the mean $\% \pm$ SEM of cells expressing different patterns in 4 replicate experiments. Different letters above the bars denote statistically significant difference $(\mathrm{P}<0.05)$ within the same pattern. 


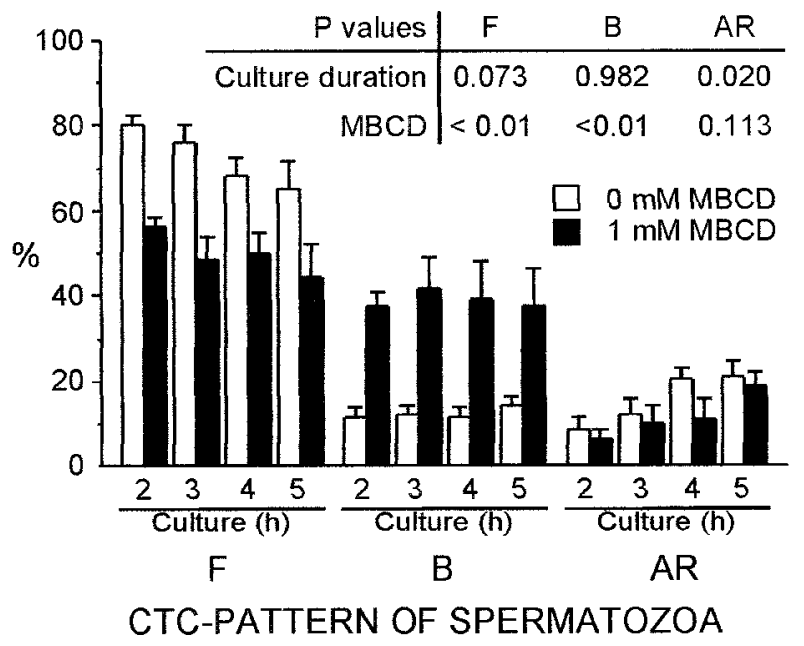

Fig. 2. Functional status of boar spermatozoa during culture for $5 \mathrm{~h}$ in mM199-PVA containing $1 \mathrm{mM}$ MBCD as determined by CTC assay. Suspensions were cultured in the presence or absence of $1 \mathrm{mM}$ MBCD in mM199-PVA for 2-5 $\mathrm{h}$ in an atmosphere of $5 \% \mathrm{CO}_{2}$ in air at $39 \mathrm{C}$. Data are presented as the mean $\% \pm$ SEM of cells expressing different patterns in 4 replicate experiments. $P$ values from 2-way ANOVA are shown in the figure.

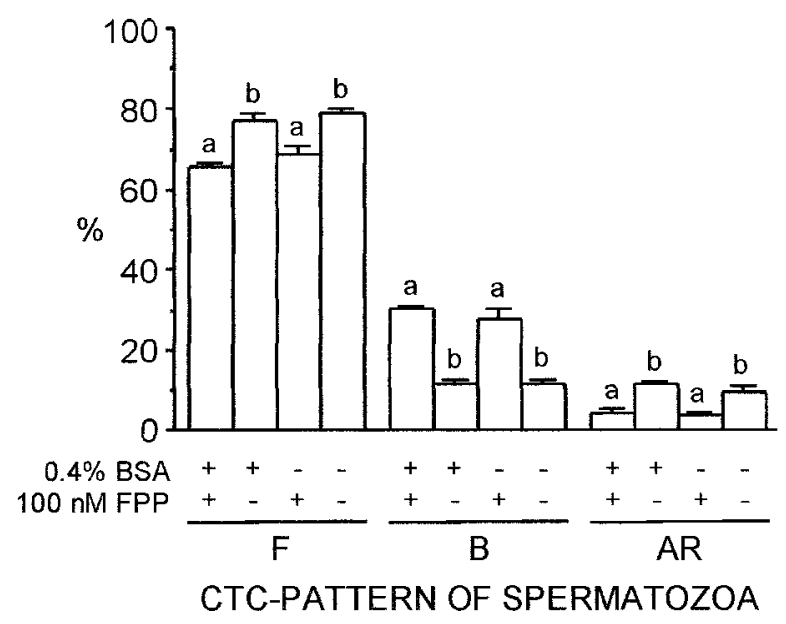

Fig. 3. Effect of FPP in the absence of BSA on sperm response as determined by CTC assay. Suspensions were cultured in the absence or presence of $100 \mathrm{nM}$ FPP in mM199-BSA or mM199-PVA for $2 \mathrm{~h}$ in an atmosphere of $5 \% \mathrm{CO}_{2}$ in air at $39 \mathrm{C}$. Data are presented as the mean $\% \pm$ SEM of cells expressing different patterns in 5 replicate experiments. Different letters above the bars denote statistically significant difference $(\mathrm{P}<0.05)$ within the same pattern.

presence of FPP regardless of the absence or presence of BSA. This evidence shows that sperm capacitation was induced and spontaneous acrosome reaction was inhibited in the presence of

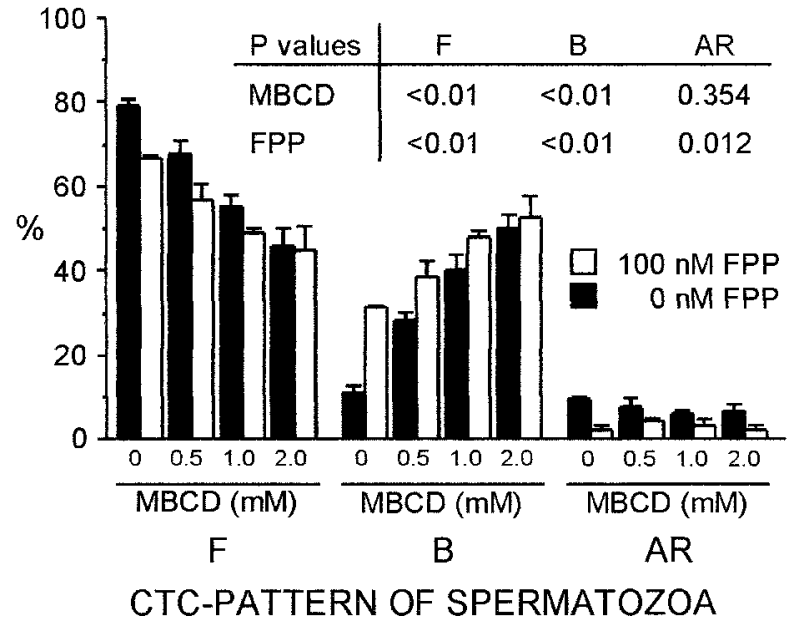

Fig. 4. Effect of FPP in the presence of MBCD in mM199PVA on sperm response as determined by CTC assay. Suspensions were cultured in various concentrations of FPP ( 0 and $100 \mathrm{nM})$ and MBCD $(0$, $0.5,1$ and $2 \mathrm{mM}$ ) in mM199-PVA for $2 \mathrm{~h}$ in an atmosphere of $5 \% \mathrm{CO}_{2}$ in air at $39 \mathrm{C}$. Data are presented as the mean $\% \pm$ SEM of cells expressing different patterns in 3 replicate experiments. $P$ values from 2-way ANOVA are shown in the figure.

FPP even in a protein-free mM199.

In the last experiment, spermatozoa were cultured in mM199-PVA supplemented with various concentrations of $\operatorname{MBCD}(0,0.5,1$ and 2 $\mathrm{mM}$ ) and FPP (0 and $100 \mathrm{nM})$. An accelerative effect of MBCD and FPP on sperm capacitation was observed even in the presence of FPP and MBCD, respectively (Fig. 4), but the stimulatory effect of FPP on capacitation seemed to be neutralized in the presence of higher concentrations ( 1 and $2 \mathrm{mM}$ ) of MBCD. Furthermore, although an inhibitory effect of FPP on spontaneous acrosome reaction was observed even in the presence of MBCD, the incidence of acrosome-reacted cells did not change among different concentrations of MBCD.

\section{Discussion}

In the present study, the capacitation and acrosome reaction of boar spermatozoa were assessed by CTC fluorescence assay, which was firstly described for mouse spermatozoa by Saling and Storey [22]. This assay is based on the transfer of neutral and uncomplexed CTC into the intracellular compartments and on the binding to the intracellular free calcium [23]. The CTCcalcium complex preferentially binds to 
hydrophobic regions of cell membrane resulting in a pattern of membrane staining characteristic of various transitional phases of destabilization, indicated in the literature by the letters $\mathrm{F}$ (uncapacitated, acrosome intact), B (capacitated, acrosome intact) and AR (acrosome reacted) [24]. It has been demonstrated in the mouse [25-27] and pig [21] that the so-called B-pattern of staining correlates with changes characteristic of capacitated cells (also see the review by Watson and Green [28]), although it remains unclear in detail how the change in the CTC-pattern of staining corresponds to the state of capacitation.

The present results determined by CTC fluorescence assay demonstrated that capacitation of boar spermatozoa was accelerated in the presence of MBCD in a protein-free medium, in a concentration-dependent manner, although the incidence of acrosome-reacted cells was not affected. Furthermore, the spontaneous acrosome reaction of spermatozoa progressively increased when the culture duration was prolonged to $5 \mathrm{~h}$. Therefore, MBCD appears to be related to the induction of the first step of boar sperm capacitation in protein-free medium. These lines of evidence are consistent with recent reports that $\mathrm{MBCD}$, a strong acceptor of cholesterol, stimulates the efflux of cholesterol from sperm membrane and induces capacitation of spermatozoa in a proteinfree medium in mice [13, 14], cattle [14] and man $[15,16]$. Further, Visconti et al. [14] showed a difference between mice and cattle in the sensitivity of spermatozoa to MBCD by analyzing protein tyrosine phosphorylation; significant tyrosine phosphorylation of bull spermatozoa was detected at higher concentrations of MBCD than in mouse cells. In the present study, the capacitationstimulating effect of MBCD was detected at 0.25 $\mathrm{mM}$, which is lower level than that observed in cattle [14]. Boar spermatozoa may be relatively sensitive to MBCD. In the present study, stimulation of the incidence of capacitated cells was stimulated dependent on the concentration of $M B C D$, but did not change during prolonged culture for $5 \mathrm{~h}$. Therefore, efflux of cholesterol from sperm membrane caused by MBCD would occur in a concentration-dependent manner and complete relatively fast. Iborra et al. [29] recently demonstrated that cholesterol desorption by $\beta$ cyclodextrin was very rapid in goat spermatozoa. In contrast, the current study shows that spontaneous acrosome reaction appears to be induced slowly in protein-free medium in pigs. In the present study, the incidence of acrosomereacted cells was never induced by exposure to MBCD in a protein-free medium, mM199-PVA. Nevertheless, since excessive efflux of cholesterol from goat sperm membrane induced acrosome reaction [29], the rate of spontaneous acrosome reaction may be associated with the degree of cholesterol efflux from sperm membrane. Further research will be required to clarify the relation between the degree of cholesterol efflux and induction of capacitation and acrosome reaction.

At the efflux of sperm cholesterol in the early step of capacitation, serum albumin (especially BSA in IVF systems) can serve as an acceptor for sperm cholesterol in other species $[4,5,11,13,14]$. The present study demonstrated that, even in the absence of BSA, FPP induced capacitation and inhibited spontaneous acrosome loss of boar spermatozoa. FPP and adenosine modify the same signal transduction pathway but act via different receptors [30]. In mice and pigs, however, FPP receptors appear to interact with stimulatory adenosine receptors in intact spermatozoa to induce capacitation and with inhibitory adenosine receptors in capacitated cells to prevent spontaneous acrosome reaction $[18,31]$. Therefore, the results of the current study demonstrate that binding of FPP to the receptors and reaction against FPP, such as stimulation of the adenylate cyclase/ cAMP signal transduction pathway [30,31], do not require the efflux of cholesterol from the sperm membrane. In the present study, as demonstrated in our previous studies $[17,18]$, the stimulatory effect of FPP on sperm capacitation was not neutralized in the presence of $0.4 \%$ BSA. Although the cholesterol content of spermatozoa was not assessed in the present study, the ability of BSA to effuse cholesterol from sperm membrane may be less than that of $1 \mathrm{mM}$ MBCD.

The mechanism for MBCD to induce capacitation after efflux of sperm membrane has not been clarified yet. As described above, Visconti et al. [14] detected a significant protein tyrosine phosphorylation in mouse and bull spermatozoa after MBCD treatment. Mouse spermatozoa also contain similar protein tyrosine phosphorylation during FPP-induced alternations [19]. In the present study, the stimulatory effect of FPP on sperm capacitation was neutralized in the presence 
of 1 and $2 \mathrm{mM} \mathrm{MBCD}$, whereas the effect of FPP was detected at 0 and $0.5 \mathrm{mM} \mathrm{MBCD}$, suggesting the possibility that MBCD and FPP induce capacitation via similar pathways in boar spermatozoa. FPP receptors located near stimulatory adenosine receptors appear to interact in intact cells to modify the adenylate cyclase/ cAMP and to induce capacitation, and FPP receptors located near inhibitory adenosine receptors also appear to interact to inhibit spontaneous acrosome reaction [18]. Cholesterol has been shown not only to stabilize the plasma membrane but also to regulate the ion pumps of the cells [32]. Efflux of sperm cholesterol by MBCD may modify the adenylate cyclase/cAMP via regulation of ion pumps, induce protein tyrosine phosphorylation and consequently induce capacitation.
In conclusion, the present study demonstrated that efflux of cholesterol from cell membrane by MBCD induced the early steps in the capacitation of boar spermatozoa, that stimulatory and inhibitive effects of FPP on capacitation and spontaneous acrosome reaction, respectively, of boar spermatozoa may not require the efflux of sperm cholesterol, and that MBCD and FPP may induce capacitation of boar spermatozoa in a protein-free medium.

\section{Acknowledgments}

I thank Okayama Prefectural Center for Animal Husbandry \& Research for supplying fresh boar semen.

\section{References}

1. Ehrenwald E, Parks JE, Foote RH. Cholesterol efflux from bovine sperm. I. Induction of the acrosome reaction with lysophosphatidylcholine after reducing sperm cholesterol. Gamete Res 1988; 20: 145-157.

2. Ehrenwald E, Parks JE, Foote RH. Cholesterol efflux from bovine sperm: II. Effect of reducing sperm cholesterol on penetration of zona-free hamster and in vitro matured bovine ova. Gamete Res 1988; 20: 413-420.

3. Zarintash RJ, Cross NL. Unesterified cholesterol content of human sperm regulates the response of the acrosome to the agonist, progesterone. Bio Reprod 1996; 55: 19-24.

4. Davis BK, Byrne R, Bedigian K. Studies on the mechanism of capacitation: albumin-mediated changes in plasma membrane lipids during in vitro incubation of rat sperm cells. Proc Nat Acad Sci USA 1980; 77: 1546-1550.

5. Go KJ, Wolf DP. Albumin-mediated changes in sperm sterol content during capacitation. Biol Reprod 1985; 32: 145-153.

6. Ehrenwald E, Foote RH, Parks JE. Bovine oviductal fluid components and their potential role in sperm cholesterol efflux. Mol Reprod Dev 1990; 25: 195-204.

7. Langlais J, Kan FW, Granger L, Raymond L, Bleau G, Roberts KD. Identification of sterol acceptors that stimulate cholesterol efflux from human spermatozoa during in vitro capacitation. Gamete Res 1988; 20: 185-201.

8. Therien I, Moreau R, Manjunath P. Major proteins of bovine seminal plasma and high-density lipoprotein induce cholesterol efflux from epididymal sperm. Biol Reprod 1998; 59: 768-776.

9. Parks JE, Ehrenwald E. Choresterol efflux from mammalian sperm ans its potential role in capacitation. In: Bavister BD, Cummins J, Roldan ERS (eds.), Fertilization in Mammals. Norwell, MA, USA: Serono Symposia; 1990: 155-167.

10. Davis BK. Timing of fertilization in mammals: sperm cholesterol/phospholipid ratio as a determinant of the capacitation interval. Proc Natl Acad Sci USA 1981; 78: 7560-7564.

11. Suzuki F, Yanagimachi Y. Changes in the distribution of intramembranous particles and filipin-reactive membrane sterols during in vitro capacitation of golden hamster spermatozoa. Gamete Res 1989; 23: 335-347.

12. Harrison RA. Capacitation mechanisms, and the role of capacitation as seen in eutherian mammals. Reprod Fert Dev 1996; 8: 581-594.

13. Choi Y-H, Toyoda Y. Cyclodextrin remove cholesterol from mouse sperm and induces capacitation in a protein-free medium. Biol Reprod 1998; 59: 1328-1333.

14. Visconti PE, Galantino-Homer $\mathbf{H}$, Ning $\mathbf{X}$, Moore GD, Valenzuela JP, Jorgez CJ, Alvarez JG, Kopf GS. Cholesterol efflux-mediated signal transduction in mammalian sperm. beta-cyclodextrins initiate transmembrane signaling leading to an increase in protein tyrosine phosphorylation and capacitation. J Biol Chem 1999; 274: 3235-3242.

15. Osheroff JE, Visconti PE, Valenzuela JP, Travis AJ, Alvarez J, Kopf GS. Regulation of human sperm 
capacitation by a cholesterol efflux-stimulated signal transduction pathway leading to protein kinase A-mediated up-regulation of protein tyrosine phosphorylation. Mol Hum Reprod 1999; 5: 10171026.

16. Cross NL. Effect of methyl-beta-cyclodextrin on the acrosomal responsiveness of human sperm. Mol Reprod Dev 1999; 53: 92-98.

17. Funahashi H, Asano A, Fujiwara T, Nagai T, Niwa K, Fraser LR. Both fertilization promoting peptide and adenosine stimulate capacitation but inhibit spontaneous acrosome loss in ejaculated boar spermatozoa in vitro. Mol Reprod Dev 2000; 54: 1-8.

18. Funahashi H, Nagai T. Modulation of the function of boar spermatozoa via adenosine and fertilization promoting peptide receptors reduce the incidence of polyspermic penetration into porcine oocytes. Biol Reprod 2000; 63: 1157-1163.

19. Adeoya-Osiguwa SA, Fraser LR. Fertilization promoting peptide and adenosine, acting as first messengers, regulate cAMP production and consequent protein tyrosine phosphorylation in a capacitation-dependent manner. Mol Reprod Dev 2000; 57: 384-392.

20. Funahashi H, Cantley TC, Day BN. Synchronization of meiosis in porcine oocytes by exposure to dibutyryl cyclic AMP improves developmental competence following in vitro fertilization. Biol Reprod 1997; 57: 49-53.

21. Wang WH, Abeydeera LR, Fraser LR, Niwa K. Functional analysis using chlortetracycline fluorescence and in vitro fertilization of frozenthawed ejaculated boar spermatozoa incubated in a protein-free chemically defined medium. J Reprod Fert 1995; 104: 305-313.

22. Saling PM, Storey BT. Mouse gamete interactions during fertilization in vitro. Chlortetracycline as a fluorescent probe for the mouse sperm acrosome reaction. J Cell Biol 1979; 83: 544-555.
23. Tsien TY. Fluorescent indicators of ion concentrations. In: Taylor DL, Wang Y-L (eds.), Method in Cell Bioology vol. 30, Fluorescence microscopy of living cells in culture. Part B. Quantitative fluorescence microscopy-imaging and spectroscopy. New York, Academic Press; 1989: 127-156.

24. Johnson LA, Weitze KF, Fiser P, Maxwell WMC. Storage of boar semen. Anim Reprod Sci 2000; 62: 143-172.

25. Ward CR, Storey BT. Determination of the time course of capacitation in mouse spermatozoa using a chlortetracycline fluorescence assay. Dev Biol 1984; 104: 287-296.

26. Fraser LR, Harrison RAP, Herod JE. Characterisation of a decapacitation factor associated with epididymal mouse spermatozoa. J Reprod Fert 1990; 89: 135-148.

27. Fuller SJ, Whittingham DG. Capacitation-like changes occur in mouse spermatozoa cooled to low temperatures. Mol Reprod Dev 1997; 46: 318-324.

28. Watson PF, Green CE. Cooling and capacitation of boar spermatozoa: what do they have in common? In: Johnson LA, Guthrie HD (eds.), Boar Semen Preservation IV. Lawrence, KS, USA, Allen Press, Inc.; 2000: 53-60.

29. Iborra A, Companyo M, Martinez P, Morros A. Cholesterol efflux promotes acrosome reaction in goat spermatozoa. Biol Reprod 2000; 62: 378-383.

30. Adeoya-Osiguwa SA, Dudley RK, Hosseini R, Fraser LR. FPP modulates mammalian sperm function via TCP-11 and the adenylyl cyclase/ cAMP pathway. Mol Reprod Dev 1998; 51: 468-476.

31. Fraser LR, Adeoya-Osiguwa SA. Modulation of adenylyl cyclase by FPP and adenosine involves stimulatory and inhibitory adenosine receptors and G proteins. Mol Reprod Dev 1999; 53: 459-471.

32. Yeagle PL. Lipid regulation of cell membrane structure and function. FASEB J 1989; 3: 1833-1842. 